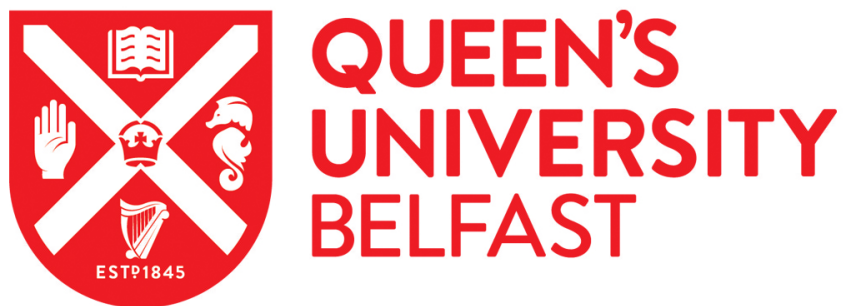

\section{A psychosocial intervention for individuals with advanced chronic kidney disease: a feasibility randomised controlled trial}

Jenkins, Z. M., Tan, E. J., O'Flaherty, E., Knowles, S., Thompson, D. R., Ski, C. F., Rossell, S. L., Coco, C., lerino, F. L., Gock, H., \& Castle, D. J. (2021). A psychosocial intervention for individuals with advanced chronic kidney disease: a feasibility randomised controlled trial. Nephrology, 26(5), 442-453.

https://doi.org/10.1111/nep.13850

Published in:

Nephrology

Document Version:

Peer reviewed version

Queen's University Belfast - Research Portal:

Link to publication record in Queen's University Belfast Research Portal

Publisher rights

Copyright 2021 Wiley. This work is made available online in accordance with the publisher's policies. Please refer to any applicable terms of use of the publisher.

\section{General rights}

Copyright for the publications made accessible via the Queen's University Belfast Research Portal is retained by the author(s) and / or other copyright owners and it is a condition of accessing these publications that users recognise and abide by the legal requirements associated with these rights.

Take down policy

The Research Portal is Queen's institutional repository that provides access to Queen's research output. Every effort has been made to ensure that content in the Research Portal does not infringe any person's rights, or applicable UK laws. If you discover content in the Research Portal that you believe breaches copyright or violates any law, please contact openaccess@qub.ac.uk. 


\section{NEPHROLOGY}

\section{A psychosocial intervention for individuals with advanced chronic kidney disease: a feasibility randomised controlled trial}

\begin{tabular}{|c|c|}
\hline Journal: & Nephrology \\
\hline Manuscript ID & NEP-2020-0808.R1 \\
\hline Manuscript Type: & Original Article \\
\hline $\begin{array}{r}\text { Date Submitted by the } \\
\text { Author: }\end{array}$ & $\mathrm{n} / \mathrm{a}$ \\
\hline Complete List of Authors: & $\begin{array}{l}\text { Jenkins, Zoe; St Vincent's Hospital Melbourne Pty Ltd, Mental Health; } \\
\text { University of Melbourne, Psychiatry } \\
\text { Tan, Eric; Swinburne University of Technology, Centre for Mental Health; } \\
\text { St Vincent's Hospital, Department of Psychiatry } \\
\text { O'Flaherty, Emmet; St Vincent's Hospital Melbourne, Nephrology } \\
\text { Knowles, Simon; Swinburne University of Technology, Psychology } \\
\text { Thompson, David; Queen's University Belfast, Nursing and Midwifery } \\
\text { Ski, Chantal; University of Suffolk, Integrated Care Academy } \\
\text { Rossell, Susan; Swinburne University of Technology, Centre for Mental } \\
\text { Health } \\
\text { Coco, Carolee; St Vincent's Hospital Melbourne Pty Ltd, Mental Health } \\
\text { Ierino, Francesco; Austin Health, The University of Melbourne, } \\
\text { Nephrology } \\
\text { Gock, Hilton; St. Vincent's Hospital, Nephrology } \\
\text { Castle, David; St Vincent's Hospital Melbourne Pty Ltd, Mental Health }\end{array}$ \\
\hline Subject Category: & Chronic Kidney Disease \\
\hline Keywords: & $\begin{array}{l}\text { Psychosocial, Randomised controlled trial, chronic kidney disease (CKD), } \\
\text { Depression, Anxiety }\end{array}$ \\
\hline
\end{tabular}

\section{SCHOLARONE Manuscripts}


1 A psychosocial intervention for individuals with advanced chronic kidney disease: a

2 feasibility randomised controlled trial

3 Short running head: Psychosocial intervention for advanced CKD

4 Zoe M Jenkins ${ }^{1,2}$, Eric J Tan ${ }^{1,3}$, Emmet O’Flaherty ${ }^{4}$, Simon Knowles ${ }^{1,2,5}$, David R

5 Thompson ${ }^{2,6}$, Chantal F Ski ${ }^{2,9}$, Susan L Rossell ${ }^{1,3}$, Carolee Coco ${ }^{1}$, Francesco L Ierino ${ }^{7,8}$,

6 Hilton Gock $^{7}$, David J Castle ${ }^{1,2}$

7

$8 \quad{ }^{1}$ Mental Health Service, St. Vincent's Hospital, Melbourne, Australia

$9 \quad{ }^{2}$ Department of Psychiatry, University of Melbourne, Melbourne, Australia

$10 \quad{ }^{3}$ Centre for Mental Health, Swinburne University, Melbourne, Australia

$11 \quad{ }^{4}$ Department of Nephrology, St. Vincent's Hospital, Melbourne, Australia

$12{ }^{5}$ Department of Psychology, Swinburne University of Technology, Melbourne, Australia

13 6School of Nursing and Midwifery, Queen's University Belfast, Belfast, UK

$14 \quad{ }^{7}$ Department of Nephrology, St Vincent's Hospital, Melbourne, Australia

$15{ }^{8}$ Department of Nephrology, University of Melbourne, Melbourne, Australia

$16{ }^{9}$ University of Suffolk, Integrated Care Academy, Ipswich, UK

18 Corresponding author: Zoe Jenkins, St. Vincent's Mental Health Services, PO Box 2900,

19 Fitzroy, VIC 3065, Australia. Email: zoe.jenkins@svha.org.au Telephone: +613 92313426 


\section{Trial registrations:}

2 Australia and New Zealand Clinical Trials Registry (ANZCTR): ACTRN12615000810516

$3(05.07 .15)$.

4 http://anzctr.org.au/Trial/Registration/TrialReview.aspx?ACTRN=12615000810516

\section{$5 \quad$ Keywords}

6 Psychosocial; randomised controlled trial; chronic kidney disease; depression; anxiety

\section{$7 \quad$ Funding and declarations of interest}

8 This work was supported through the Australian Government's Collaborative Research

9 Networks (CRN; Grant ID: 2012013000549) program and Kidney Health Australia (Grant

10 ID: KHA2018-DC). EJT and SLR are in receipt of Early Career (GNT1142424) and Senior

11 Research (GNT1154651) Fellowships respectively from the National Health and Medical

12 Research Council of Australia. DJC has received grant monies for research from Eli Lilly,

13 Janssen Cilag, Roche, Allergen, Bristol-Myers Squibb, Pfizer, Lundbeck, Astra Zeneca,

14 Hospira; Travel Support and Honoraria for Talks and Consultancy from Eli Lilly, Bristol-

15 Myers Squibb, Astra Zeneca, Lundbeck, Janssen Cilag,Pfizer, Organon, Sanofi-Aventis,

16 Wyeth, Hospira, Servier, Seqirus; and is a current Advisory Board Member for Lu AA21004:

17 Lundbeck; Varenicline: Pfizer; Asenapine: Lundbeck; Aripiprazole LAI: Lundbeck;

18 Lisdexamfetamine: Shire; Lurasidone: Servier; Brexpiprazole: Lundbeck; Treatment

19 Resistant Depression: LivaNova. He is founder of the Optimal Health Program, currently

20 operating as Optimal Wellness. He is on the board of The Mental health Foundation of

21 Australia. He does not knowingly have stocks or shares in any pharmaceutical company. No

22 other authors report any conflicts of interest. 
1

2 Aim: The current study evaluated the feasibility and preliminary efficacy of a psychosocial 3 intervention, the Kidney Optimal Health Program, in reducing symptoms of depression and 4 anxiety in individuals with advanced chronic kidney disease.

5 Methods: Patients with stage 4 or 5 chronic kidney disease were randomised to either a nine-

6 session psychosocial intervention program or usual care. Feasibility was assessed through

7 recruitment and retention rates and program acceptability. Participants completed

8 assessments of depression, anxiety and psychosocial health at baseline and at 3-, 6- and 12-

9 month follow-up. A repeated-measures ANOVA was used to compare groups on outcomes

10 over time.

11 Results: 128 patients were screened for eligibility; 84 consented to participant and were 12 randomised to receive the intervention $(N=42)$ or usual care $(N=42) .27(32.1 \%)$ participants 13 withdrew prior to baseline assessment. Of those who completed the baseline assessment $14(N=57)$, trial retention was high $(75.4 \%$ at 3 -months, $80.7 \%$ at 6 -months and $70.2 \%$ at 12 12-month follow-up compared to the usual care group $(N=13)$.

18 Conclusion: The results support the feasibility of the Kidney Optimal Health Program intervention in recruitment, retention and program acceptability with an improved screening randomised controlled trial is warranted. 


\section{Introduction}

2 Chronic kidney disease (CKD) is a global healthcare problem. The Global Burden of Disease

3 study estimated that between 5-10 million people worldwide die from kidney disease each

4 year, with incidence steadily increasing ${ }^{1}$. Approximately $10 \%$ of Australians present with at

5 least one biomedical indicator of $\mathrm{CKD}^{2}$ and over $40 \%$ of people aged 75 or older are living

6 with the disease ${ }^{3}$. Moreover, CKD is a risk factor for developing other illnesses including

7 cardiovascular disease, dementia and stroke, often resulting in a profound disease burden for

8 patients and accounting for $2-3 \%$ of the annual healthcare budget in developed countries ${ }^{4}$.

9 Symptoms of kidney disease are often not evident until up to $90 \%$ of kidney function is lost 2 ;

10 consequently, many people remain unaware of their condition until an advanced stage, often

11 requiring treatment in the form of dialysis or kidney transplantation to prevent fatality.

The transition to dialysis treatment from stage 4 to stage 5 CKD requires substantial

13 lifestyle adjustments including dietary and scheduling restrictions and physiological

14 monitoring; balancing of which can prove stressful for patients. In addition, stage $5 \mathrm{CKD}$

15 (also referred to as end stage kidney disease (ESKD), is often associated with unpleasant

16 symptoms such as fatigue, pruritus, constipation, sleep disturbance and swelling of the feet

17 and ankles which contribute to an overall reduction in quality of life (QoL) ${ }^{5}$. The impact of

18 ESKD on QoL is detrimental to the extent that an average patient would be willing to give up

1910 years of life on dialysis in exchange for 4 years with normal kidney function ${ }^{4}$. Patients

20 with advanced CKD, who are not yet dependent on dialysis, experience a comparable overall

21 burden of symptoms and low QoL, which may be related to their anxiety about the condition

22 including possibility of renal replacement therapy.

23 Self-management is a pertinent concept for patients with advanced CKD, given the

24 active participation in treatments necessary to control the signs and symptoms of their 
1 condition. As such, patients with advanced CKD need to be confident in their capability of

2 managing their long-term health condition. Self-efficacy, a mediator of self-management, has

3 been associated with enhanced QoL in patients with ESKD ${ }^{6}$. Another important protective

4 factor in how patients self-manage and adjust to a diagnosis of advanced CKD is perceived

5 social support. Low levels of social support have been associated with decreased treatment

6 compliance ${ }^{7}$ and higher mortality rate in patients with advanced $\mathrm{CKD}^{8}$, with suggestions

7 that social factors are relevant to 'personalised renal medicine' ${ }^{9}$. Just as self-efficacy and

8 perceived social support have been identified as health determinants for patients with CKD; a

9 patient's perception of how the disease interferes with their lives, defined as illness

10 perception, is also an important indicator of wellbeing and QoL. Previous investigations into

11 illness perceptions in patients with CKD found that poorer illness perceptions increased maladaptive coping strategies, which in turn increased both depression and anxiety ${ }^{10}$.

The disease management burden of advanced CKD and its impact on QoL, social support and illness perceptions means that patients often experience psychological distress, with depression and anxiety affecting a large proportion of patients with ESKD, at higher incidence than other chronic diseases ${ }^{11}$. Depression has been associated with an array of

17 negative prognostic outcomes including impaired functional capacity and higher rates of hospitalisation ${ }^{12}$, as well as greater dialysis withdrawal resulting in earlier mortality ${ }^{13}$.

19 Though less investigated, anxiety is also common in patients with $\mathrm{CKD}^{14}$, with similar 20 prevalence across predialysis and patients undergoing dialysis ${ }^{15}$. Elevated anxiety has been 21 demonstrated to negatively impact QoL ${ }^{15}$, and may arise in predialysis patients as a result of

22 a loss of control over reduced abilities, sexual dysfunction, frequent hospital visits and/or the 23 threat of dialysis in the near future ${ }^{16,17}$. In renal units, most psychiatric services remain 24 reactive, treating those who are referred with obvious symptoms, representing only a small 25 proportion of those affected. 
Given the significant impact depression, anxiety and psychosocial factors have on

2 QoL and treatment prognosis in this population, there is a critical and under-recognised need

3 for a specialised intervention for management and treatment of psychological comorbidities

4 in individuals with advanced $\mathrm{CKD}$, especially during the challenging transition to life on

5 dialysis. Moreover, there is a dearth of research into management and prevention of

6 depression and anxiety in individuals with advanced CKD. Previous studies have

7 demonstrated that psychosocial interventions (an intervention that combines both

8 psychological and social components within its framework ${ }^{18}$ have been effective in

9 decreasing depression and anxiety in other chronic disease populations, yet a recent

10 systematic review found that there are few studies investigating psychosocial interventions in

11 individuals with advanced $\mathrm{CKD}^{19}$.

This study aimed to evaluate the feasibility of the Kidney Optimal Health Program

13 (KOHP) to improve the psychosocial health of advanced CKD patients, compared to usual

14 care. KOHP is an adaptation of a psychosocial support program, the Optimal Health Program

15 (OHP $)^{20}$, tailored to patients with kidney disease. The OHP uses a collaborative therapy

16 framework designed to address psychosocial and physical dimensions of health that has

17 demonstrated effectiveness in improving mental health outcomes in psychiatric populations 1820.

The primary objective of the current study was to determine the feasibility of

conducting an 8-week psychosocial intervention in patients with advanced CKD through the

following objectives to determine the appropriateness of the intervention for a definitive

RCT:

i) Explore trial recruitment and retention rates.

ii) Assess the acceptability of the KOHP intervention. 
1 The secondary objectives were to evaluate preliminary efficacy of KOHP in

2 improving depression, anxiety, QoL, self-efficacy, social and workplace functioning, and

3 illness perceptions in individuals with advanced CKD. It was hypothesized that:

$4 \quad$ i) Recruitment and retention rates would demonstrate feasibility and that participants

5 would report KOHP as acceptable.

6

ii) KOHP would demonstrate preliminary efficacy in improving depression, anxiety

7 and psychosocial outcomes in individuals with advanced CKD.

\section{Methods}

10 Research design and setting

11 This was a parallel pilot randomised controlled trial (RCT) to evaluate the feasibility of

12 delivering the KOHP to individuals with advanced CKD. The KOHP was delivered as a nine-

$13(8+1)$ week individualised support program using health promotion strategies and was

14 compared to usual care. Recruitment was conducted between January 2015 to December

152018 at the nephrology unit of St Vincent's Hospital, a large metropolitan teaching hospital

16 in Melbourne, Australia.

17 An executive steering committee consisting of a nephrologist, a specialist renal nurse,

18 psychologists, psychiatrists, nurses and a health economist oversaw project planning,

19 procedures and ongoing data collation. The study protocol was approved by the St Vincent's

20 Hospital Human Research Ethics Committee (HREC-A 019/14) and written informed consent

21 was obtained from all participants. The trial was conducted in accordance with the

22 Declaration of Helsinki.

23 Participants 
1 Participants were recruited from the nephrology department through out-patient clinic

2 attendance or clinician referral. Eligible participants met the following inclusion criteria: 1)

3 Stage 4 or $5 \mathrm{CKD}$, evidenced by an eGFR of $<30 \mathrm{ml} / \mathrm{min}$ confirmed from medical records; 2 )

418 years or older; 3) able to converse in English without an interpreter or professional

5 assistance; and 4) absence of established cognitive deficits impairing their ability to learn

6 from the intervention. Exclusion criteria included: 1) presence of developmental disability or

7 amnestic syndrome impairing their ability to learn from the intervention; 2) participants

8 returning to dialysis following a failed renal transplant; and 3) comorbid serious illness as

9 defined by the treating physician. Individuals who were seeking a mental health professional

10 or taking psychotropic medications were not excluded from participating.

Randomisation, allocation and blinding

12 Following the initial screening and gaining of consent, participants were allocated to either

13 intervention or control group via a computer-generated block randomisation sequence created

14 by an independent person not directly involved in the study. Participants were randomised

15 immediately after consent and before baseline assessments. Due to the nature and length of

16 the intervention, it was not possible to blind either patient or investigator to the intervention

17 allocation.

Intervention: The Kidney Optimal Health Program (KOHP)

The KOHP was delivered in nine $(8+1$ booster session $)$ sequential sessions based on a

20 structured workbook (see Table 1.). Sessions were approximately one hour in duration and

21 held weekly, apart from the 'booster' session, which was held three months after session eight. Each participant was allocated to one KOHP trained facilitator who conducted the 23 intervention.

In summary, session 1 introduced the KOHP within the six domains of 'optimal health'; considering the balance of mental, emotional, social, occupational, physical and 
1 spiritual needs of a person. Sessions 2 and 3 initiated development of a health plan exploring

2 the implications and potential complications of advanced CKD and dialysis in terms of

3 strengths and vulnerabilities in session 2 and understanding and monitoring disease impact in

4 session 3. The focus of session 4 was on metabolic monitoring and medication management.

5 Session 5 expanded the health plan to include key CKD treatment partnerships and supports

6 in the community and online. Session 6 focused on change enhancement in terms of

7 understanding past events and establishing new proactive avenues for change. The aim of

8 session 7 was goal setting via creative problem solving and planning around the complexities

9 of renal failure and dialysis. Session 8 strategised wellbeing maintenance and sustainability

10 related to the CKD treatment and management. The objective of the 'booster session'

11 (session 9) was to consolidate progress via reviewing health plans and reflecting on

12 achievements made toward health-related goals.

A health professional (e.g. nurse, psychologist) trained in the collaborative therapy approach (2-day workshop plus regular supervision and fidelity checks) facilitated each session. The facilitator drew on advanced CKD-specific information in concordance with individual circumstances. Further, if a participant identified severe anxiety and/or depression

17 or suicidal ideation at any time during the study, they were referred to an appropriate mental health service. Patient participation was discontinued based upon self-request and/or feedback from the referred treating mental health service. Participants had the option of 20 participating in sessions via face to face meeting, telephone or video call.

\section{$21 \quad$ Standard care}

22 The participants allocated to the control group received care as usual by the nephrology team at St. Vincent's Hospital which included education by the doctors, nurses, social worker and/or CKD educator on topics such as dietary management, fluid intake and medication 25 management. 
1

Insert Table 1. here

2 Outcome measures

3 Primary outcomes: feasibility and acceptability

4 i) Recruitment and retention rates were recorded at baseline, 3, 6, and 12 months follow-up.

5 Reasons for withdrawal were recorded as one of the following: 1) Illness/death; 2) Drop-

6 out/relocation; 3) Loss of contact; 4) Failure to return questionnaire; 5) Kidney

7 transplant/recovery of kidney function.

8 ii) Perceived acceptability of the KOHP was assessed at 3-months post-baseline after

9 completion of the KOHP using the Treatment Evaluation Inventory-Short Form (TEI-SF) ${ }^{21}$.

10 Secondary outcomes: preliminary efficacy

11 Secondary outcome assessments took place at baseline, 3, 6, and 12 months' post-baseline.

12 All assessments were conducted by mailing out the questionnaires to participants and

13 providing them with reply-paid envelopes to return the completed questionnaires.

14 Depression and anxiety (Hospital Anxiety and Depression Scale, HADS) ${ }^{22}$.

15 The HADS consists of 14 items with a 4-point scale producing two subscales: anxiety and 16 depression. Higher scores on the anxiety and depression subscales (made up of 7 items each)

17 reflect increased levels of anxiety and depression ${ }^{22}$. The HADS is a reliable self-report

18 instrument with sufficient internal validity ${ }^{23}$

19 Kidney Disease Quality of Life Instrument -Short Form (KDQoL-SF) ${ }^{24}$.

20 The KDQoL consists of the generic SF-36 health status survey ${ }^{25}$ as well as 11 multi-item

21 scales focused on QoL issues specific to patients with kidney disease, with higher 
1 transformed scores reflecting better quality of life to produce a summary score for general

2 QoL (SF-36) and a Kidney Disease Component Summary (KDCS).

3 General Self-Efficacy Scale (GSE) ${ }^{26}$.

4 Self-efficacy is defined as the belief of a person in his or her ability to organize and execute

5 certain behaviours that are necessary in order to produce given attainments. The GSE consists

6 of 10 items with responses marked on a 4-point scale, with higher scores indicative of higher

7 self-efficacy.

8 Work and Social Adjustment Scale (WSAS) ${ }^{27}$.

9 The WSAS consists of 5 questions related to various areas of impairment, with responses

10 made on a 0 to 8 scale and higher scores indicating poorer functional impairment ${ }^{27}$.

11 Brief Illness Perception Questionnaire (Brief-IPQ) ${ }^{28}$

12 The Brief-IPQ assesses the cognitive and emotional representations of illness and consists of

138 items that assess cognitive and emotional elements of illness representation including;

14 identity, consequences, cause, time, cure or control, and emotional representations ${ }^{28}$, with

15 higher scores indicating a poorer representation of illness.

17 Statistical analyses

18 Data analyses were performed using SPSS (IBM, SPSS Statistics Version 25). Means and

19 standard deviations were calculated for continuous variables, and frequencies were measured

20 for categorical variables. Demographic characteristics and baseline scores on assessments

21 outcomes were compared between groups using chi-squared analysis for categorical variables

22 and independent samples $t$-tests for continuous variables. 
1

2 least one assessment time point (47.4\%), resulting in incomplete required data for the

3

4

5

6

7

8

9

10

11

12

13

14

15

16

17

18

19

20

21

22

23

There were a large amount of cases with unreturned follow-up questionnaires for at secondary outcomes, the complete case analysis approach was adopted ${ }^{29}$. Therefore, only the data and results from the 30 full completion cases are reported for preliminary efficacy. Prior to analysis, data was screened for missing variables and univariate and multivariate normality. Normality was assessed using the Shapiro-Wilks test and examination of skewness/kurtosis values. All continuous variables were found to be normally distributed with no missing values. Differences in assessment outcomes between the control and intervention groups were tested by a 2 x 4 way analysis of variance (ANOVA) [group (KOHP, control) x assessment (BL, 3m, 6m, 12m)] for each assessment outcome.

Greenhouse-Geisser [epsilon] corrections were used to correct for violations of sphericity in the data. Differences between groups and across time were established and post-hoc pairwise comparisons with Bonferroni adjustments. All significances were set at $p<.05$.

Results

128 patients were screened for eligibility; 84 consented to participant and were randomised to receive the KOHP intervention or usual care (see Figure 1.). The demographic and clinical characteristics of those who completed the baseline assessment $(n=57)$ in each group are detailed in Tables 2 and 3. There were no differences between groups on demographic characteristics or kidney function, as measured by eGFR or the proportion of patients on either haemodialysis or peritoneal dialysis. Moreover, there were similar proportions of individuals in each group receiving pharmacological treatment for depression or anxiety at baseline assessment and the proportion of participants with a with previous psychiatric 
1 diagnosis or a and history of treatment by a MH professional did not differ between groups 2 (see Table 3.).- 
Insert Table 2 here. 
1

Insert Table 3. here
2

3 Primary outcomes: feasibility

$4 \quad$ i) Recruitment and retention rates

5 In individuals who were eligible and able to participate in the intervention, $77.1 \%$ consented

6 to participate and were randomised to either receive the KOHP or usual care (see Figure 1.).

7 Of those randomised to receive KOHP, $64.3 \%$ received the intervention and completed the

8 baseline assessment. Reasons for withdrawal prior to baseline for KOHP and control groups

9 included illness/death (33.3\% vs $25.0 \%$ ), self-withdrawal/relocation ( $33.3 \%$ vs $25.0 \%)$, loss

10 of contact ( $20 \%$ vs $33.3 \%$ ), failure to return the baseline assessment in the mail $(13.3 \%$ of

11 KOHP group) or kidney transplant (16.6\% of control group), respectively. Follow-up

12 assessment completion rates by the KOHP and control groups were similar at the 3-month

13 (70.4\% vs $80.0 \%)$, 6-month (70.4\% vs $90.0 \%)$ and 12 -month $(62.9 \%$ vs $76.7 \%)$ time points.

14 Reasons for withdrawal post-baseline were also comparable between KOHP and control

15 groups; failure to return questionnaire (41.7\% vs $42.9 \%)$, illness/death (50.0\% vs 42.9\%),

16 relocation (8.3\% of KOHP group) or kidney transplant (14.3\% of control group).

17

ii) Acceptability of the KOHP intervention 
1

2

3 Of the 27 participants who completed the intervention, $18(66.6 \%)$ returned the TEI-SF

4 assessments in the mail. Table 4. provides a summary of the perceived acceptability (TEI-SF)

5 as reported by the participants. After completion of the program, $77.8 \%$ of participants

6 believed that KOHP was an acceptable way to improve their wellbeing, $81.5 \%$ of participants

7 were willing to engage in the program to improve their wellbeing, $83.4 \%$ believe that the

8 program was effective, $66.7 \%$ believe $\mathrm{KOHP}$ was likely to result in permanent improvement

9 and $83.3 \%$ had a positive reaction to KOHP (see Table 4.).

10 Secondary outcomes: preliminary efficacy of KOHP

11 The results between groups and over time are detailed in Table 5. The two-way repeated-

12 measures ANOVA yielded a significant group by time interaction, $F(2.07,58.05)=4.74, p=$

130.012 , and a significant main effect of time, $F(2.03,58.05)=4.52, p=0.014$, on levels of

14 depression. 
1

2

3 Post-hoc pairwise comparisons between time points in the KOHP group revealed a significant

4 reduction in depression between baseline to 3-months $[p=.042,95 \% \mathrm{CI}(.10,4.52)]$, baseline

5 to 12 -months $[p=.002,95 \% \mathrm{CI}(1.71,5.98)]$ and between 6-months to 12 -months $[p=.033$,

$695 \%$ CI $(.19,3.66)]$ (see Figure 2.), but not between 3-months to 6-months $[p=.51,95 \%$ CI (-

$71.61, .84)]$. There were no other significant interactions between group and time on

8 assessment outcomes over the intervention or follow-up period.

$9 \quad$ Additionally, one participant who received the KOHP intervention group reported

10 discontinuation of their anxiety medication (pregabalin) over the course of the trial (at the 6-

11 month time point). There were no other changes to pharmacological treatments for depression

12 or anxiety by participants in either group. 
1 Insert Figure 2 here: Depression scores of participants in KOHP and control groups over

2 time. Data are expressed as mean (SD). ${ }^{*} p<.05,{ }^{* *} p<.005$ from baseline for KOHP group;

$3 \# p<.05$ from 6-months for KOHP group (post hoc Tukey’s test). 


\section{Discussion}

2 The current study reports on the evaluation of the feasibility and preliminary efficacy of a

3 novel psychosocial intervention, the KOHP, which aimed to improve the mental health of

4 individuals living with advanced CKD. Assessment of recruitment and retention rates and

5 acceptability of the KOHP intervention support our primary hypothesis and confirm the

6 feasibility of a future definitive RCT. Our secondary hypothesis that KOHP would provide

7 preliminary efficacy was partly supported. There was a reduction depressive symptoms in

8 advanced CKD patients, however there were no improvements in anxiety or psychosocial 9 factors.

10 Feasibility

11 The recruitment rate from eligible participants was high yet we identified a disproportionately

12 large withdrawal rate prior to baseline assessment. The reasons for withdrawal prior to

13 baseline did not differ between the intervention and controls groups, with a large proportion

14 due to illness and patient mortality. However, there were a substantial proportion of patients

15 who electively withdrew or were lost to follow-up. This could be due to participants being

16 provided an inadequate description of the study requirements during screening. This

17 highlights a need to enhance the screening protocol of patients to confirm willingness to

18 complete the extensive outcome assessments. Intervention and control group study adherence

19 was high post-baseline assessment, with the most common reason for withdrawal being either

20 illness or death.

21 Acceptability of the KOHP intervention was high, with the majority of participants

22 reporting willingness to engage, belief in efficacy of the program and an overall positive

23 reaction to KOHP. Approximately half of the participants expressed that discomfort would be

24 experienced during the program, which is an expected process of the KOHP intervention. The 
1 program utilises elements of both motivational interviewing and self-determination theory in

2 order to improve identified aspects of wellbeing, which draw on cognitive dissonance as a

3 form of motivation. Cognitive dissonance may arise if a participant becomes aware that their

4 beliefs do not align with their behaviours, resulting in feelings of discomfort ${ }^{30}$. Furthermore,

5 there were no unintended effects or potential harms found during the pilot study. Given the

6 limited research on interventions targeted towards psychosocial health in advanced CKD, the

7 current findings support the feasibility and acceptability of a definitive RCT of KOHP in

8 individuals with advanced CKD.

$9 \quad$ Preliminary efficacy

10 Over the course of the trial, individuals randomised to the intervention demonstrated a

11 significantly greater reduction in the primary outcome of depression, as compared to those

12 allocated to the usual care group. Depressive symptoms in the KOHP group significantly

13 decreased between baseline assessment and post-intervention (3-month assessment), and

14 decreased further at the 12-month follow-up. This supports the potential utility of

15 psychosocial interventions, and specifically KOHP, for the reduction of depressive symptoms

16 in this population. While some immediate benefit as a result of direct facilitator-related

17 influence cannot be ruled out, particularly given similar indications in other intervention

18 studies ${ }^{31 \theta}$, there was a significant difference in depressive symptoms between groups

19 following the booster session held at 6-months. This indicated a beneficial effect from the

20 follow-up session which may have reinforced implementation of health management

21 strategies developed throughout the intervention.

22 In contrast, no associated changes were observed in overall assessment of anxiety.

23 Given the comorbid nature of depression and anxiety, it was hypothesised that both

24 depression and anxiety would be significantly improved. This hypothesis was not supported 
1 by the current findings, despite evidence that previous psychosocial interventions have

2 reported some beneficial effect on anxiety symptoms in advanced CKD populations ${ }^{19}$.

3 Similarly, there was no significant improvement in the secondary psychosocial measures of

4 QoL (both general and disease-specific), self-efficacy, work and social adjustment or illness

5 perceptions. Possible reasons for the disparity in our pilot include the progressive impact of

6 lifestyle adjustments on anxiety and QoL that may accumulate over time, the burden of

7 medications that can have side effects and inadequate sample size. The ideal time to

8 demonstrate the intervention effect on anxiety and QoL may be after 12 months when

9 medical management and physical symptoms are optimised, stabilised, and synergised with

10 the reduction in depression. Therefore, further evaluation of these outcomes in a larger

11 sample size and possibly for a longer duration is required.

\section{Limitations}

13 As this was a feasibility evaluation, our analyses were not statistically powered to detect

14 clinically meaningful change in outcomes, which could have also precluded the emergence of

15 significant outcomes of KOHP on other assessed variables (e.g. QoL). Feasibility and

16 acceptability of the KOHP may have also varied between the different delivery modalities

17 (i.e. phone vs face-to-face) which we were unable to compare in the current study. Moreover,

18 baseline levels of cognition were also not assessed, which could have impacted on feasibility

19 of the KOHP, particularly with noted cognitive deficits in CKD patients ${ }^{32}+$. Future work

20 should consider inclusion of an explicit measure of level of disease activity or associated

21 disease-related demands (e.g. number and duration of dialysis visits). Moreover, future

22 investigations should investigate potential differences in program efficacy between patients

23 undergoing dialysis and those not undergoing dialysis, given the substantial lifestyle

24 adjustments that accompany dialysis treatment. 


\section{Conclusion and future directions}

2 Overall, despite these limitations, this evaluation confirms the feasibility and acceptability of

3 a psychosocial intervention RCT in individuals with advanced CKD. Moreover, it provides

4 preliminary and important support for its efficacy, and the expansion of this research with a

5 broader and larger sample size. The prevalence of psychological distress in advanced CKD

6 populations is profound, negatively impacts prognostic outcomes and is a key intervention

7 target. Management of mental and psychosocial health is of upmost clinical importance for

8 individuals with $\mathrm{CKD}$, given the high rates of comorbid depression ${ }^{11}$ that are associated with

9 poorer quality of life and treatment outcomes ${ }^{13,15}$. The research team is currently conducting

10 an expanded RCT, with an additional hospital as a recruitment site-, which will provide an

11 evaluation of efficacy of the KOHP intervention in improving psychosocial health and an

12 assessment of healthcare utilisation of individuals with advanced CKD. - This is the next step

13 towards obtaining the necessary evidence to support the translation of KOHP into renal

14 services to be offered to patients as standard care. 
2 1. Wang H, Naghavi M, Allen C, et al. Global, regional, and national life expectancy,

3

4

5

62 Australian Institute of Health \& Welfare. Cardiovascular disease, diabetes and all-cause mortality, and cause-specific mortality for 249 causes of death, 1980-2015: a systematic analysis for the Global Burden of Disease Study 2015. The lancet. 2016;388(10053):1459-1544. chronic kidney disease: Australian facts mortality. Canberra: AIHW;2014.

3. Australian Institute of Health \& Welfare. Diabetes and chronic kidney disease as risks for other diseases: Australian Burden of Disease Study 2011. Canberra: AIHW;2016.

4. Couser WG, Remuzzi G, Mendis S, Tonelli M. The contribution of chronic kidney disease to the global burden of major noncommunicable diseases. In. United States: Nature Publishing Group; 2011:1258.

5. Murtagh FEM, Addington-Hall J, Higginson IJ. The Prevalence of Symptoms in EndStage Renal Disease: A Systematic Review. Advances in Chronic Kidney Disease. 2007;14(1):82-99.

6. Tsay S-L. Self-efficacy training for patients with end-stage renal disease. Journal of Advanced Nursing. 2003;43(4):370-375.

7. Kimmel PL. Psychosocial factors in adult end-stage renal disease patients treated with hemodialysis: Correlates and outcomes. American Journal of Kidney Diseases. 2000;35(4, Supplement):S132-S140.

8. Christensen AJ, Wiebe JS, Smith TW, Turner CW. Predictors of survival among hemodialysis patients: effect of perceived family support. Health Psychol. 1994;13(6):521. 
19 McClellan WM, Doran JJ. Friends, social networks, and progressive chronic kidney

2

3

4

5

6

8

9

10 disease. Kidney Int. 2015;87(4):682-684.

10. Knowles S, Swan L, Salzberg M, Castle D, Langham R. Exploring the relationships between health status, illness perceptions, coping strategies and psychological morbidity in a chronic kidney disease cohort. The American journal of the medical sciences. 2014;348(4):271-276.

11. Palmer S, Vecchio M, Craig JC, et al. Prevalence of depression in chronic kidney disease: systematic review and meta-analysis of observational studies. Kidney Int. 2013;84(1):179-191.

12. Hedayati SS, Jiang W, O'Connor CM, et al. The association between depression and chronic kidney disease and mortality among patients hospitalized with congestive heart failure. Am J Kidney Dis. 2004;44(2):207-215.

13. Lacson E, Jr., Li NC, Guerra-Dean S, Lazarus M, Hakim R, Finkelstein FO. Depressive symptoms associate with high mortality risk and dialysis withdrawal in incident hemodialysis patients. Nephrol Dial Transplant. 2012;27(7):2921-2928.

14. Feroze U, Martin D, Reinapatton A, Kalantarzadeh K, Kopple JD. Mental health, depression, and anxiety in patients on maintenance dialysis. 2010.

15. Lee YJ, Kim MS, Cho S, Kim SR. Association of depression and anxiety with reduced quality of life in patients with predialysis chronic kidney disease. Int J Clin Pract. 2013;67(4):363-368.

16. Gyamlani G, Basu A, Geraci S, et al. Depression, screening and quality of life in chronic kidney disease. Am J Med Sci. 2011;342(3):186-191.

17. Kimmel PL. Depression in patients with chronic renal disease: what we know and what we need to know. Journal of psychosomatic research. 2002;53(4):951-956. 
1 18. Thompson DR, Ski CF. Psychosocial interventions in cardiovascular disease-what are

2

3

4

5

6

7

8

9

10

11

12

13 they. Eur J Prev Cardiol. 2013;20:916-917.

19. Pascoe MC, Thompson DR, Castle DJ, McEvedy SM, Ski CF. Psychosocial interventions for depressive and anxiety symptoms in individuals with chronic kidney disease: Systematic review and meta-analysis. Frontiers in psychology. 2017;8:992.

20. Gilbert MM, Chamberlain JA, White CR, et al. Controlled clinical trial of a selfmanagement program for people with mental illness in an adult mental health servicethe Optimal Health Program (OHP). Australian Health Review. 2012;36(1):1-7.

21. Newton J, Sturmey P. Development of a short form of the Treatment Evaluation Inventory for acceptability of psychological interventions. Psychol Rep. 2004;94.

22. Zigmond AS, Snaith RP. The hospital anxiety and depression scale. Acta psychiatrica Scandinavica. 1983;67(6):361-370.

23. Spinhoven P, Ormel J, Sloekers P, Kempen G, Speckens A, Van Hemert A. A validation study of the Hospital Anxiety and Depression Scale (HADS) in different groups of Dutch subjects. Psychol Med. 1997;27(2):363-370.

24. Hays RD, Kallich JD, Mapes DL, Coons SJ, Carter WB. Development of the kidney disease quality of life (KDQOL TM) instrument. Quality of life Research. 1994;3(5):329-338.

25. Ware Jr JE, Sherbourne CD. The MOS 36-item short-form health survey (SF-36): I. Conceptual framework and item selection. Medical care. 1992:473-483.

26. Jerusalem M, Schwarzer R. Generalized self-efficacy scale. Measures in health psychology: A user's portfolio Causal and control beliefs. 1995:35-37.

27. Mundt J, Marks I, Shear K, Greist J. The work and social adjustment scale: a simple measure of impairment in functioning. Br J Psychiatry. 2002;180. 
1 28. Broadbent E, Petrie KJ, Main J, Weinman J. The brief illness perception

2 questionnaire. Journal of psychosomatic research. 2006;60(6):631-637.

3 29. Jakobsen JC, Gluud C, Wetterslev J, Winkel P. When and how should multiple

4 imputation be used for handling missing data in randomised clinical trials-a practical guide with flowcharts. BMC medical research methodology. 2017;17(1):162.

$6 \quad 30 . \quad$ Festinger L. A theory of cognitive dissonance. Vol 2: Stanford university press; 1957

$7 \quad 30 \underline{1}$. Contreras NA, Lee S, Tan EJ, Castle DJ, Rossell SL. How is cognitive remediation training perceived by people with schizophrenia? A qualitative study examining personal experiences. Journal of Mental Health. 2016;25(3):260-266.

$103+2$. Brodski J, Rossell SL, Castle DJ, Tan EJ. A Systematic Review of Cognitive Impairments Associated With Kidney Failure in Adults Before Natural Age-Related Changes. Journal of the International Neuropsychological Society. 2019;25(1):101114. 
1 Table 1. Kidney Optimal Health Program (KOHP) - contents and objectives

\begin{tabular}{|c|c|c|c|}
\hline Session & Title & Contents & Objectives \\
\hline One & What is health? & $\begin{array}{l}\text { a) What is optimal health? } \\
\text { b) Behaviour can influence } \\
\text { our health } \\
\text { c) The health wheel } \\
\text { d) Introduction to health } \\
\text { plans } 1,2,3\end{array}$ & $\begin{array}{l}\text { Understand what is involved in KOHP } \\
\text { Provide definition of optimal health } \\
\text { Consider how their behaviour influences } \\
\text { their health } \\
\text { Complete self-assessment }\end{array}$ \\
\hline Two & $\begin{array}{l}\text { "I Can Do" } \\
\text { model part } 1 \text { - } \\
\text { strengths and } \\
\text { vulnerabilities }\end{array}$ & $\begin{array}{l}\text { a) Revision of session } 1 \\
\text { b) Overview of "I Can Do" } \\
\text { model } \\
\text { c) Understanding our } \\
\text { strengths and vulnerabilities } \\
\text { d) Introduction to Health } \\
\text { Plan } 1\end{array}$ & $\begin{array}{l}\text { Understand the "I Can Do" Model } \\
\text { Complete their "I Can Do" Model } \\
\text { Attempt to identify their strengths and } \\
\text { vulnerabilities } \\
\text { Understand principles of Health Plan } 1\end{array}$ \\
\hline Three & $\begin{array}{l}\text { "I Can Do" } \\
\text { model Part } 2 \text { - } \\
\text { Stressors and } \\
\text { Strategies }\end{array}$ & $\begin{array}{l}\text { a) Revision of "I Can Do" } \\
\text { model } \\
\text { b) Stressors and stress } \\
\text { c) Strategies and their } \\
\text { effectiveness } \\
\text { d) Introduction to Health } \\
\text { Plan } 2\end{array}$ & $\begin{array}{l}\text { Build understanding of "I Can Do" } \\
\text { Model } \\
\text { Identify stressors - positive and negative } \\
\text { Explore and monitor early warning signs } \\
\text { Understand strategies to manage stress } \\
\text { Understand principles of Health Plan } 2\end{array}$ \\
\hline
\end{tabular}




\begin{tabular}{|c|c|c|c|}
\hline Four & Medication & $\begin{array}{l}\text { a) Revision of session } 3 \\
\text { b) Effective use of } \\
\text { medication } \\
\text { c) Monitoring medication } \\
\text { d) Metabolic monitoring }\end{array}$ & $\begin{array}{l}\text { Identify }+/- \text { aspects of medication } \\
\text { Review medication monitoring } \\
\text { Understand value of metabolic } \\
\text { monitoring }\end{array}$ \\
\hline Five & $\begin{array}{l}\text { Collaborative } \\
\text { partners }(\mathrm{CP}) \\
\text { and strategies }\end{array}$ & $\begin{array}{l}\text { a) Revision of session } 4 \\
\text { b) Collaborative partners } \\
\text { c) Collaborative strategies } \\
\text { d) Introduction to Health } \\
\text { Plan } 3\end{array}$ & $\begin{array}{l}\text { Understand importance of CPs } \\
\text { Develop an "Eco Map" } \\
\text { Identify roles of people/supports as CPs } \\
\text { Identify strategies to develop CPs } \\
\text { Understand principles of Health Plan } 3\end{array}$ \\
\hline Six & $\begin{array}{l}\text { Change } \\
\text { enhancement }\end{array}$ & $\begin{array}{l}\text { a) Revision of session } 5 \\
\text { b) Timeline activity - } \\
\text { understanding past events } \\
\text { c) Revision of health wheel } \\
\text { d) Visioning and goal setting }\end{array}$ & $\begin{array}{l}\text { Understand the health time line } \\
\text { Explore concept of Sub-optimal Health } \\
\text { and Episode of Illness } \\
\text { Revisit Health Wheel } \\
\text { Explore what change means to them }\end{array}$ \\
\hline Seven & $\begin{array}{l}\text { Visioning and } \\
\text { goal setting }\end{array}$ & $\begin{array}{l}\text { a) Revision of session } 6 \\
\text { b) Creative problem solving } \\
\text { c) Goal setting } \\
\text { d) Reflection and celebration }\end{array}$ & $\begin{array}{l}\text { Identify a change and what it means } \\
\text { Explore key steps in problem solving } \\
\text { Understand principles of goal setting } \\
\text { Plan to set a goal and acknowledge } \\
\text { achievements }\end{array}$ \\
\hline Eight & $\begin{array}{l}\text { Maintaining } \\
\text { wellbeing }\end{array}$ & $\begin{array}{l}\text { a) Revision of session } 7 \\
\text { b) Review of health plans }\end{array}$ & $\begin{array}{l}\text { Understand Health Plans } 1,2 \& 3 \\
\text { Revise and update plans }\end{array}$ \\
\hline
\end{tabular}




\begin{tabular}{|l|l|l|l|} 
& & c) Review health journal & Understand Health Journal \\
& & d) Introduce \& plan booster & Plan for booster session \\
\hline \multirow{3}{*}{ Booster } & Session & a) Revision and catch up & Identify current health status \\
& What is my & b) Where are you now? & Review and update Health Plans \\
health like now? & \& 3 & Understand how Health Plans maintain \\
& d) Acknowledge & Celebrate achievements \\
\hline
\end{tabular}


1 Table 2. Participant demographic characteristics at baseline assessment.

\begin{tabular}{|c|c|c|c|}
\hline Participant characteristic & Usual care $(n=30)$ & KOHP $(n=27)$ & $p$-value \\
\hline Age & $59.78 \pm 13.19$ & $60.8 \pm 10.19$ & 0.747 \\
\hline Gender & & & 0.342 \\
\hline Female & $16(53.3 \%)$ & $11(40.7 \%)$ & \\
\hline Male & $14(46.7 \%)$ & $16(59.3 \%)$ & \\
\hline Ethnicity & & & 0.749 \\
\hline Caucasian & $24(80.0 \%)$ & $22(81.5 \%)$ & \\
\hline Other European & $2(6.7 \%)$ & $3(11.1 \%)$ & \\
\hline Other/Missing & $4(13.3 \%)$ & $2(7.4 \%)$ & \\
\hline Education & & & 0.809 \\
\hline Primary school & $1(3.3 \%)$ & - & \\
\hline Secondary school & $14(46.7 \%)$ & $12(44.4 \%)$ & \\
\hline Undergraduate & $3(10.0 \%)$ & $2(7.4 \%)$ & \\
\hline Postgraduate & $7(23.3 \%)$ & $6(22.2 \%)$ & \\
\hline TAFE & $4(13.3 \%)$ & $4(14.8 \%)$ & \\
\hline Other & $1(3.3 \%)$ & $3(11.1 \%)$ & \\
\hline Employment & & & 0.892 \\
\hline Full-time & $6(20.0 \%)$ & $6(22.2 \%)$ & \\
\hline Part-time & $4(13.3 \%)$ & $5(18.5 \%)$ & \\
\hline Home duties & $3(10.0 \%)$ & $1(3.7 \%)$ & \\
\hline Unemployed & $3(10.0 \%)$ & $2(7.4 \%)$ & \\
\hline Unable to work due to illness & $4(13.3 \%)$ & $5(18.5 \%)$ & \\
\hline Retired/Other & $10(33.3 \%)$ & $8(29.6 \%)$ & \\
\hline
\end{tabular}




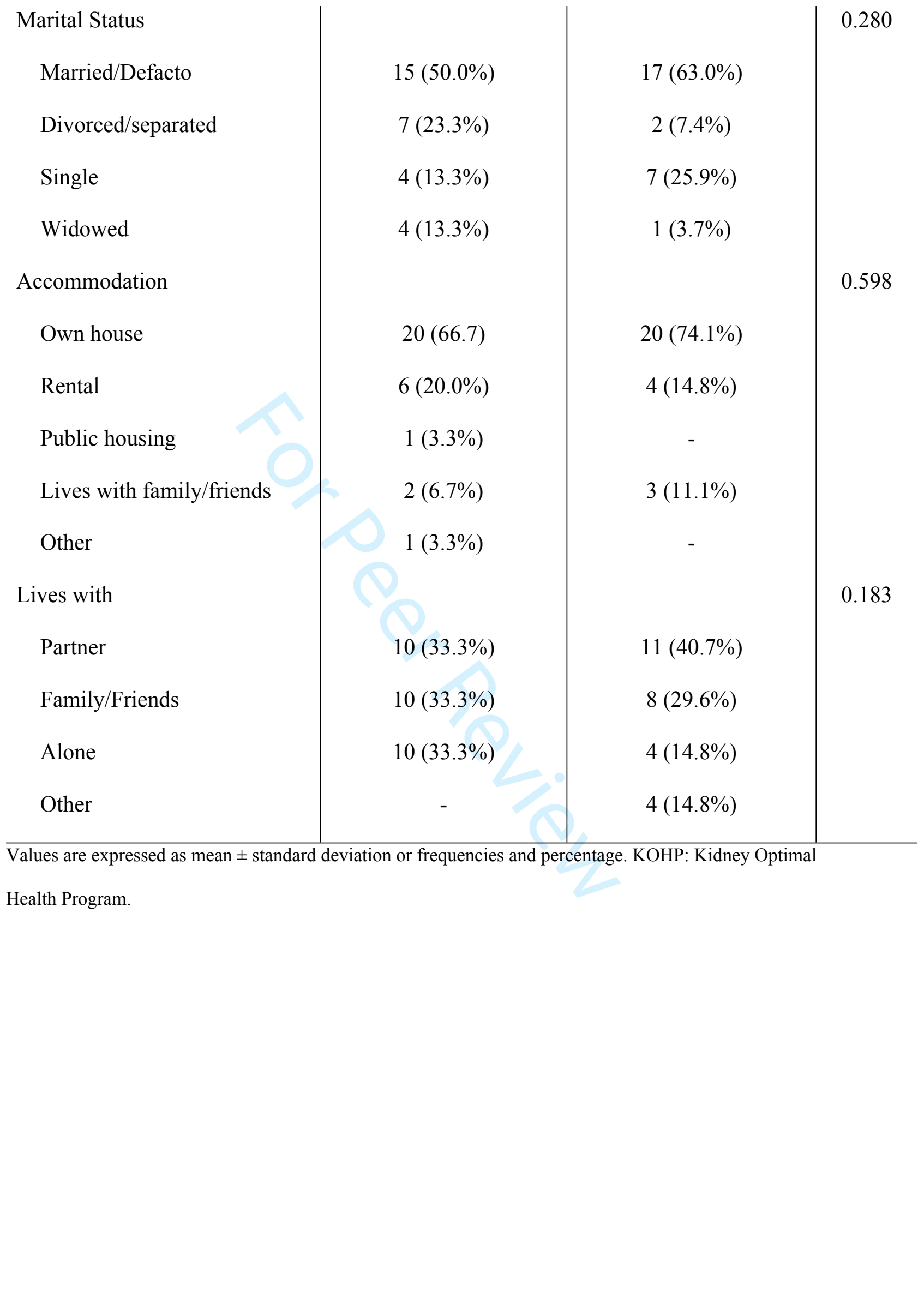


1 Table 3. Participant clinical characteristics at baseline assessment.

\begin{tabular}{|c|c|c|c|}
\hline Participant characteristic & $\begin{array}{l}\text { Usual care } \\
\qquad(n=30)\end{array}$ & $\begin{array}{l}\text { КОНР } \\
(n=27)\end{array}$ & $p$-value \\
\hline eGFR & $9.97 \pm 3.86$ & $10.37 \pm 3.67$ & 0.688 \\
\hline Dialysis status & & & 0.444 \\
\hline On Haemodialysis & $11(36.7 \%)$ & $13(48.1 \%)$ & \\
\hline On Peritoneal dialysis & $15(50.0 \%)$ & $9(33.3 \%)$ & \\
\hline Not on dialysis & $4(13.3 \%)$ & $5(18.5 \%)$ & \\
\hline Smoking status & & & 0.318 \\
\hline Never smoked & $21(70.0 \%)$ & $17(63.0 \%)$ & \\
\hline Former smoker & $9(30.0 \%)$ & $7(25.9 \%)$ & \\
\hline $1-10 \mathrm{CPD}$ & - & $2(7.4 \%)$ & \\
\hline $11-20 \mathrm{CPD}$ & & $1(3.7 \%)$ & \\
\hline Alcohol consumption & & & 0.979 \\
\hline Don't drink at all & $15(50.0 \%)$ & $14(51.9 \%)$ & \\
\hline Drink once a week or less & $13(43.3 \%)$ & $11(40.7 \%)$ & \\
\hline \multicolumn{4}{|l|}{ Drink every day in moderate } \\
\hline amounts & $2(6.7 \%)$ & $2(7.4 \%)$ & \\
\hline \multicolumn{4}{|l|}{ Undergoing pharmacological } \\
\hline treatment for depression or anxiety & $\underline{8(26.7 \%)}$ & $9(33.3 \%)$ & $\underline{0.773}$ \\
\hline Previous psychiatric diagnosis & $5(16.7 \%)$ & $6(22.2 \%)$ & 0.596 \\
\hline Depressive disorder & $4(13.3 \%)$ & $3(11.1 \%)$ & \\
\hline Anxiety disorder & - & $2(7.4 \%)$ & \\
\hline Bipolar disorder & $1(3.3 \%)$ & - & \\
\hline
\end{tabular}


Schizoaffective disorder

Previously seen $\mathrm{MH}$ professional

Currently seeing MH professional

Previously spent time in hospital for

$\mathrm{MH}$

Presented to ED in past 12 months

\begin{tabular}{ccc}
- & $1(3.7 \%)$ & \\
$10(33.3 \%)$ & $12(44.4 \%)$ & 0.390 \\
$1(3.3 \%)$ & - & 1.00 \\
$2(6.7 \%)$ & $1(3.7 \%)$ & 1.00 \\
$15(50.0 \%)$ & $10(37.0 \%)$ & 0.325 \\
\hline
\end{tabular}

1 Values are expressed as mean \pm standard deviation or frequencies and percentage. KOHP: Kidney Optimal

2 Health Program; eGFR: estimated glomerular filtration rate; CPD: cigarettes per day; MH: mental health; ED:

3 emergency department. 
1 Table 4. Summary of KOHP acceptability.

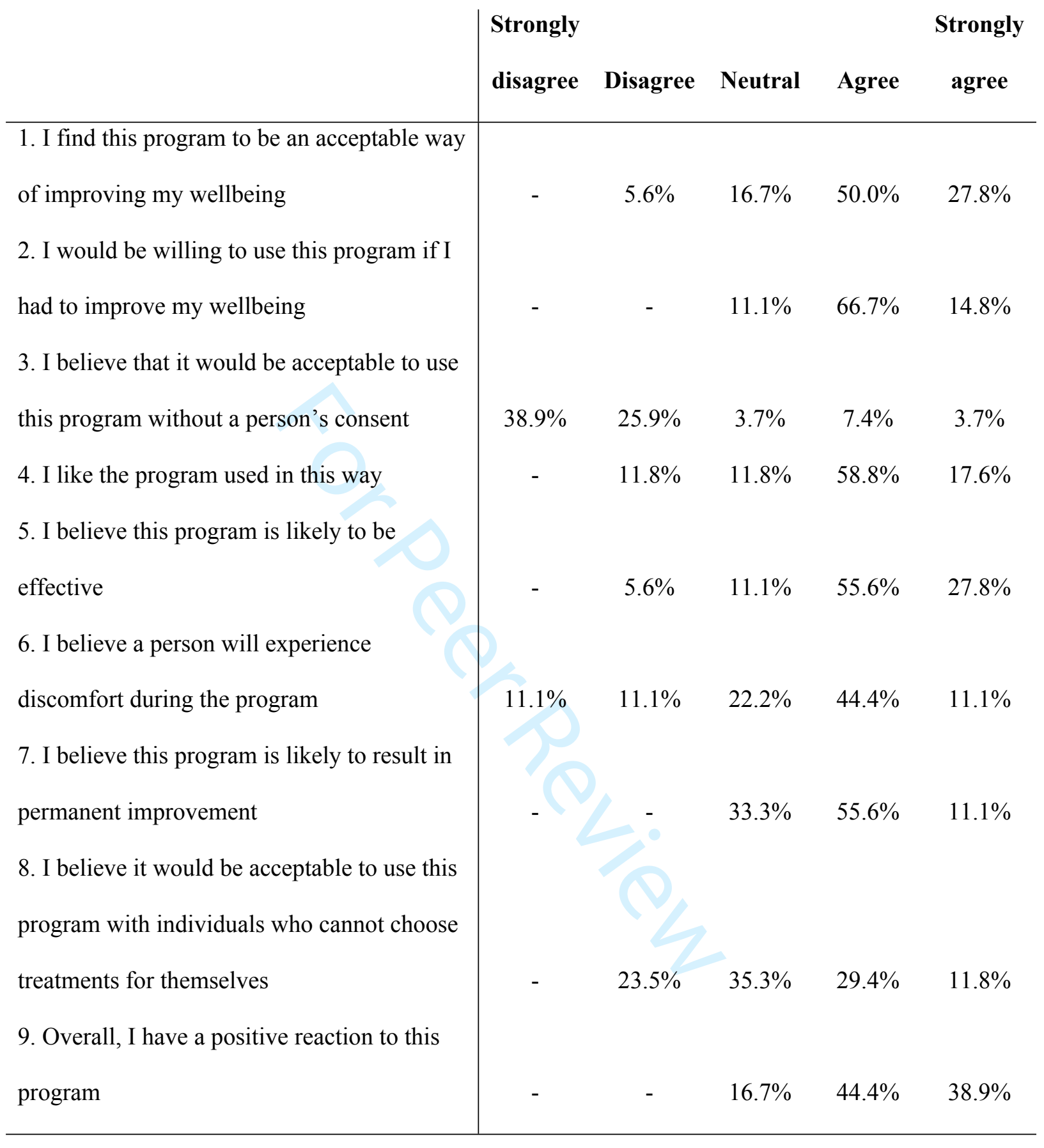


1 Table 5. Two-way ANOVA of intervention effects between groups and over time

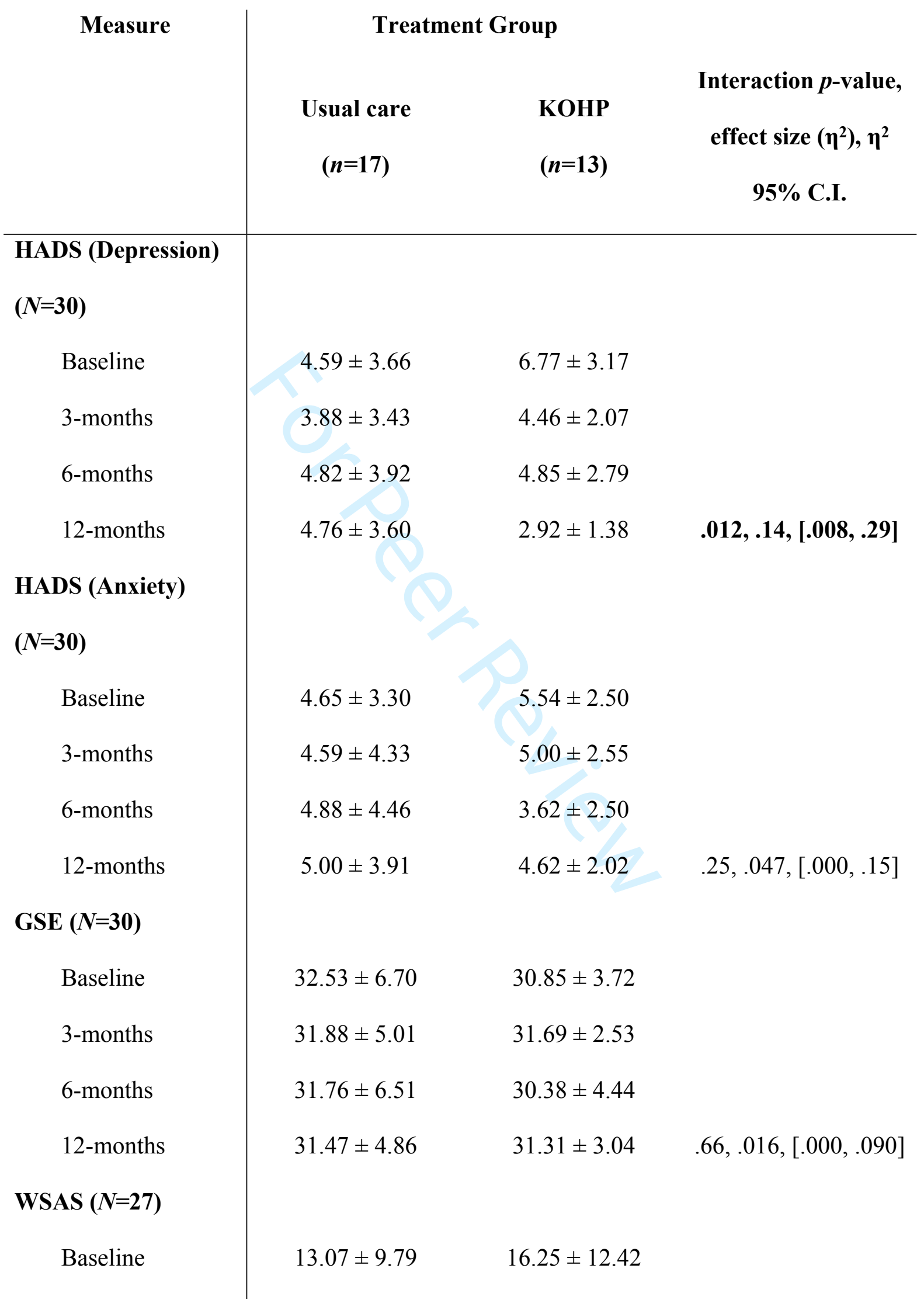


3-months

$13.53 \pm 10.25$

$14.20 \pm 11.39$

$13.73 \pm 10.09$

12-months

\section{Brief-IPQ $(N=28)$}

Baseline

3-months

6-months

12-months

\section{KDQoL-SF12}

$(N=\mathbf{2 0})$

Baseline*

3-months

6-months

12-months

\section{KDQoL-KDCS}

$$
(N=\mathbf{2 0})
$$

Baseline*

3-months

6-months
$42.76 \pm 11.66$

$39.81 \pm 14.74$

$39.25 \pm 12.11$

$38.31 \pm 15.40$

$64.07 \pm 20.76$

$69.77 \pm 20.36$

$73.64 \pm 16.09$

$66.67 \pm 17.44$

$72.78 \pm 11.16$

$62.71 \pm 11.12$

$71.92 \pm 14.98$

$67.37 \pm 7.48$

$76.89 \pm 11.83$

$68.81 \pm 8.14$

$$
75.18 \pm 12.61
$$

$.88, .009,[.000, .050]$

$39.31 \pm 9.20$

$40.58 \pm 9.30$

$39.92 \pm 9.92$

$38.25 \pm 13.36 \quad .78, .010,[.000, .078]$

$51.97 \pm 18.03$

$52.67 \pm 23.61$

$56.93 \pm 22.74$

$54.73 \pm 18.32 \quad .81, .017,[.000, .10]$

1 Values are expressed as mean \pm standard deviation. GSE: General Self-Efficacy Scale; WSAS: Work and Social

2 Adjustment Scale; Brief-IPQ: Brief-Illness Perceptions Questionnaire; HADS: Hospital Anxiety and Depression

3 Scale; KDQoL-SF12: Kidney Disease Quality of Life Short Form generic core; KDQoL-KDCS: Kidney Disease

$4 \quad$ Quality of Life-Kidney Disease Component Summary.*significantly different at baseline $(p<.05)$ 
Assessed for eligibility

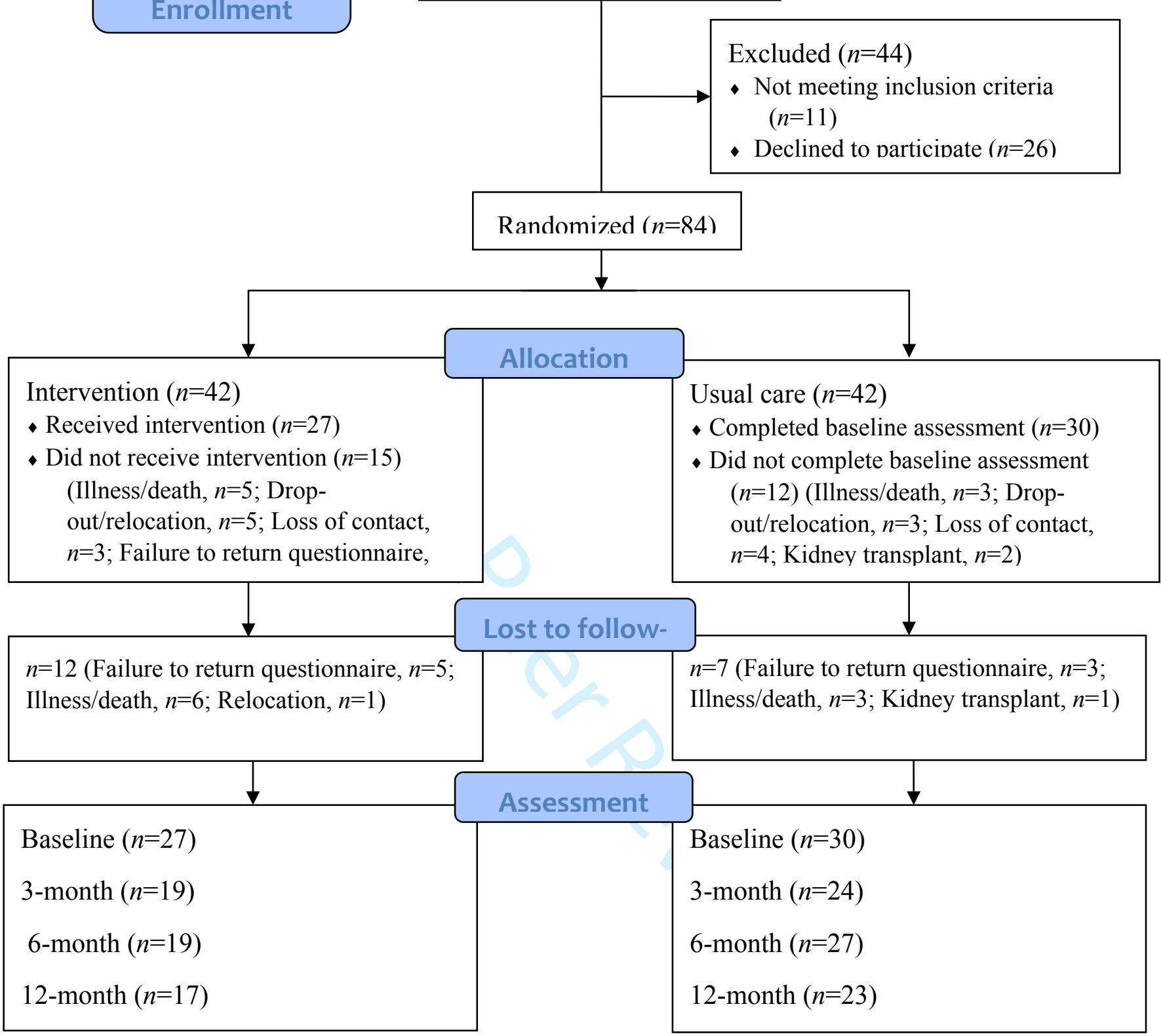

Figure 1. Participant flow chart. 


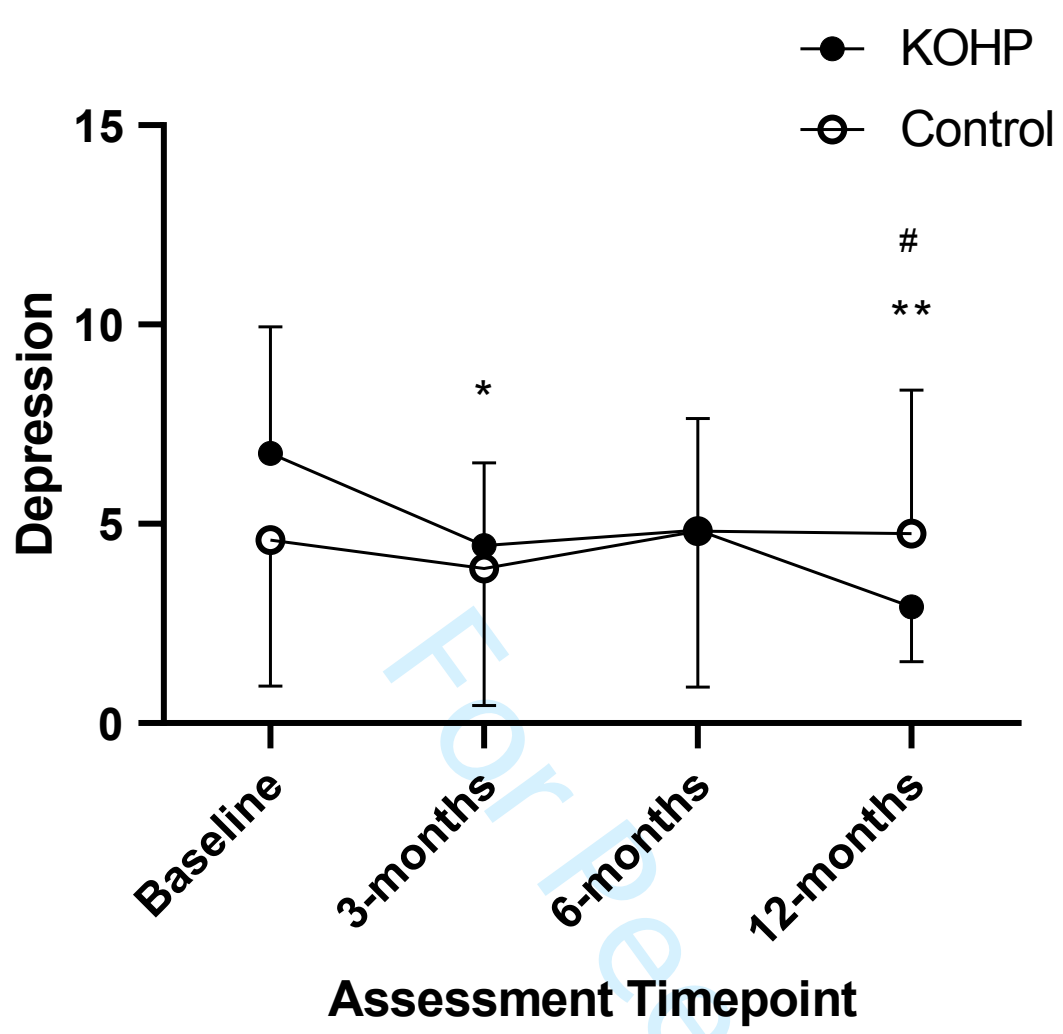

Figure 2. Depression scores of participants in KOHP and control groups over time. Data are expressed as mean (SD). ${ }^{*} p<.05,{ }^{* *} p<.005$ from baseline for KOHP group; $\# p<.05$ from 6-months for KOHP group (post hoc Tukey's test). 


\section{CONSORT 2010 checklist of information to include when reporting a pilot or feasibility trial*}

\begin{tabular}{|c|c|c|c|}
\hline Section/Topic & $\begin{array}{c}\text { Item } \\
\text { No }\end{array}$ & Checklist item & $\begin{array}{c}\text { Reported } \\
\text { on page No }\end{array}$ \\
\hline \multicolumn{4}{|l|}{ Title and abstract } \\
\hline & $1 a$ & Identification as a pilot or feasibility randomised trial in the title & Title page \\
\hline & $1 \mathrm{~b}$ & $\begin{array}{l}\text { Structured summary of pilot trial design, methods, results, and conclusions (for specific guidance see } \\
\text { CONSORT abstract extension for pilot trials) }\end{array}$ & 1 \\
\hline \multicolumn{4}{|l|}{ Introduction } \\
\hline \multirow{2}{*}{$\begin{array}{l}\text { Background and } \\
\text { objectives }\end{array}$} & $2 a$ & $\begin{array}{l}\text { Scientific background and explanation of rationale for future definitive trial, and reasons for randomised pilot } \\
\text { trial }\end{array}$ & $2-5$ \\
\hline & $2 \mathrm{~b}$ & Specific objectives or research questions for pilot trial & 5 \\
\hline \multicolumn{4}{|l|}{ Methods } \\
\hline \multirow[t]{2}{*}{ Trial design } & $3 a$ & Description of pilot trial design (such as parallel, factorial) including allocation ratio & 5 \\
\hline & $3 \mathrm{~b}$ & Important changes to methods after pilot trial commencement (such as eligibility criteria), with reasons & N/A \\
\hline \multirow[t]{3}{*}{ Participants } & $4 a$ & Eligibility criteria for participants & 6 \\
\hline & $4 \mathrm{~b}$ & Settings and locations where the data were collected & $6-7$ \\
\hline & 4c & How participants were identified and consented & 6 \\
\hline Interventions & 5 & $\begin{array}{l}\text { The interventions for each group with sufficient details to allow replication, including how and when they were } \\
\text { actually administered }\end{array}$ & $6-7$ \\
\hline \multirow[t]{3}{*}{ Outcomes } & $6 a$ & $\begin{array}{l}\text { Completely defined prespecified assessments or measurements to address each pilot trial objective specified in } \\
2 \mathrm{~b} \text {, including how and when they were assessed }\end{array}$ & $10-11$ \\
\hline & $6 \mathrm{~b}$ & Any changes to pilot trial assessments or measurements after the pilot trial commenced, with reasons & $\mathrm{N} / \mathrm{A}$ \\
\hline & $6 c$ & If applicable, prespecified criteria used to judge whether, or how, to proceed with future definitive trial & $\mathrm{N} / \mathrm{A}$ \\
\hline \multirow[t]{2}{*}{ Sample size } & $7 a$ & Rationale for numbers in the pilot trial & $\mathrm{N} / \mathrm{A}$ \\
\hline & $7 \mathrm{~b}$ & When applicable, explanation of any interim analyses and stopping guidelines & $\mathrm{N} / \mathrm{A}$ \\
\hline \multicolumn{4}{|l|}{ Randomisation: } \\
\hline \multirow{2}{*}{$\begin{array}{l}\text { Sequence } \\
\text { generation }\end{array}$} & $8 a$ & Method used to generate the random allocation sequence & 6 \\
\hline & $8 \mathrm{~b}$ & Type of randomisation(s); details of any restriction (such as blocking and block size) & 6 \\
\hline $\begin{array}{l}\text { Allocation } \\
\text { concealment }\end{array}$ & 9 & $\begin{array}{l}\text { Mechanism used to implement the random allocation sequence (such as sequentially numbered containers), } \\
\text { describing any steps taken to conceal the sequence until interventions were assigned }\end{array}$ & 6 \\
\hline
\end{tabular}




\begin{tabular}{|c|c|c|c|}
\hline \multicolumn{4}{|l|}{ mechanism } \\
\hline Implementation & 10 & $\begin{array}{l}\text { Who generated the random allocation sequence, who enrolled participants, and who assigned participants to } \\
\text { interventions }\end{array}$ & 6 \\
\hline \multirow[t]{2}{*}{ Blinding } & $11 a$ & $\begin{array}{l}\text { If done, who was blinded after assignment to interventions (for example, participants, care providers, those } \\
\text { assessing outcomes) and how }\end{array}$ & 6 \\
\hline & $11 \mathrm{~b}$ & If relevant, description of the similarity of interventions & $\mathrm{N} / \mathrm{A}$ \\
\hline Statistical methods & 12 & Methods used to address each pilot trial objective whether qualitative or quantitative & $10-11$ \\
\hline \multicolumn{4}{|l|}{ Results } \\
\hline \multirow{2}{*}{$\begin{array}{l}\text { Participant flow (a } \\
\text { diagram is strongly } \\
\text { recommended) }\end{array}$} & $13 a$ & $\begin{array}{l}\text { For each group, the numbers of participants who were approached and/or assessed for eligibility, randomly } \\
\text { assigned, received intended treatment, and were assessed for each objective }\end{array}$ & Figure 1 \\
\hline & $13 \mathrm{~b}$ & For each group, losses and exclusions after randomisation, together with reasons & Figure 1 \\
\hline \multirow[t]{2}{*}{ Recruitment } & $14 a$ & Dates defining the periods of recruitment and follow-up & 5 \\
\hline & $14 \mathrm{~b}$ & Why the pilot trial ended or was stopped & $\mathrm{N} / \mathrm{A}$ \\
\hline Baseline data & 15 & A table showing baseline demographic and clinical characteristics for each group & Table 2, 3 \\
\hline Numbers analysed & 16 & $\begin{array}{l}\text { For each objective, number of participants (denominator) included in each analysis. If relevant, these numbers } \\
\text { should be by randomised group }\end{array}$ & 12 \\
\hline $\begin{array}{l}\text { Outcomes and } \\
\text { estimation }\end{array}$ & 17 & $\begin{array}{l}\text { For each objective, results including expressions of uncertainty (such as } 95 \% \text { confidence interval) for any } \\
\text { estimates. If relevant, these results should be by randomised group }\end{array}$ & Table 5 \\
\hline Ancillary analyses & 18 & Results of any other analyses performed that could be used to inform the future definitive trial & Table 5 \\
\hline \multirow[t]{2}{*}{ Harms } & 19 & All important harms or unintended effects in each group (for specific guidance see CONSORT for harms) & 19 \\
\hline & $19 a$ & If relevant, other important unintended consequences & $\mathrm{N} / \mathrm{A}$ \\
\hline \multicolumn{4}{|l|}{ Discussion } \\
\hline Limitations & 20 & Pilot trial limitations, addressing sources of potential bias and remaining uncertainty about feasibility & 28 \\
\hline Generalisability & 21 & Generalisability (applicability) of pilot trial methods and findings to future definitive trial and other studies & 27 \\
\hline \multirow[t]{2}{*}{ Interpretation } & 22 & $\begin{array}{l}\text { Interpretation consistent with pilot trial objectives and findings, balancing potential benefits and harms, and } \\
\text { considering other relevant evidence }\end{array}$ & $26-29$ \\
\hline & $22 a$ & Implications for progression from pilot to future definitive trial, including any proposed amendments & $28-29$ \\
\hline \multicolumn{4}{|l|}{ Other information } \\
\hline Registration & 23 & Registration number for pilot trial and name of trial registry & Title page \\
\hline Protocol & 24 & Where the pilot trial protocol can be accessed, if available & $\mathrm{N} / \mathrm{A}$ \\
\hline \multirow[t]{2}{*}{ Funding } & 25 & Sources of funding and other support (such as supply of drugs), role of funders & Title page \\
\hline & 26 & Ethical approval or approval by research review committee, confirmed with reference number & 5 \\
\hline
\end{tabular}


Citation: Eldridge SM, Chan CL, Campbell MJ, Bond CM, Hopewell S, Thabane L, et al. CONSORT 2010 statement: extension to randomised pilot and feasibility trials. BMJ. 2016;355. *We strongly recommend reading this statement in conjunction with the CONSORT 2010, extension to randomised pilot and feasibility trials, Explanation and Elaboration for important clarifications on all the items. If relevant, we also recommend reading CONSORT extensions for cluster randomised trials, non-inferiority and equivalence trials, non-pharmacological treatments, herbal interventions, and pragmatic trials. Additional extensions are forthcoming: for those and for up to date references relevant to this checklist, see www.consort-statement.org. 